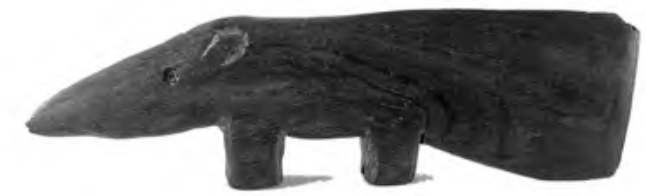

\title{
Un poco de intrahistoria, con su permiso
}

El día que Solano Benítez entró en mi casa por primera vez no me pude contener: "iSolano! Eres más alto de lo que pensaba". Su risa se precipitó sin ningún complejo y nos abrazamos como si nos conociéramos desde el colegio. Llegaba con una mochila de montaña, cargada a la espalda, llena de información. Todos me habían hablado de él. "Tienes que conocer a Solano", me decían desde Ecuador. "Tienes que conocer a Solano", me decían desde México, desde Argentina, Galicia o Cataluña. "Tienes que conocer a Solano". Antes de conocerlo ya nos conocíamos. Ya habíamos publicado una de sus obras en la revista Arquitectura, casa las Anitas, incluso sin verla. Algo que no suele suceder. Aquella tarde me abrió sus brazos, me regaló sus ideas y me confesó gran parte de sus problemas. Yo soy gallego, poco amigo de mostrar mis emociones. Desde entonces, tengo que reconocer que rompimos todas las barreras.

Ustedes se preguntarán, ¿̇ué clase de Editorial es este? No parece un comienzo muy ortodoxo tratándose de una publicación académica. Efectivamente no lo es. El rigor científico, como podrán comprobar, aparece unas páginas más adelante.

Permítanme esta licencia y abrir desde aquí algunas ventanas que puedan unir la arquitectura con la realidad, que puedan recordarnos que las obras son para vivirlas, que detrás de las obras hay personas que las piensan, las construyen y las habitan.

Un tiempo después, volaba hacia Asunción con la esperanza de que sus edificios, tan valorados, pudieran soportar una visita. No sería la primera vez que regreso de un viaje con las manos vacías, o menos llenas de lo que esperaba. Malditas revistas, cuánto las necesitamos. Nuestro trabajo como arquitectos nos obliga a desmontar dioses, mientras que nuestro esfuerzo como editores nos empuja a descubrir héroes. Así, entre contradicciones nos movemos.

Tras veintiséis horas de viaje y una escala interminable, llegué a las seis de la mañana.

Ciertamente, no eran las mejores condiciones para reconocer la belleza. Allí me esperaba Joseto, José Cubilla. Un gran arquitecto que tiempo atrás, en otro lugar, me había regalado un pequeño tapir de madera de quebracho colorado como recuerdo de nuestro encuentro. Una manera de decirle al mundo que Paraguay existe. Un símbolo de su tierra, un trozo de su cultura. Nos saludamos con cariño. No eran horas, tampoco, para aspavientos efusivos y ni él ni yo somos especialmente dramáticos. Subimos a su ranchera y comenzó a sonar la guitarra de Recuerdos de Ypacaraí, un homenaje al maestro Mangoré, mientras amanecía camino a la casa Abu. Abu, la madre de Solano, una Señora. Una señora que regresó de Perú con un camión lleno de muebles y un pedazo de vida. Los muebles que ahora conviven con la arquitectura de su hijo y la mejoran. Y abajo en el sótano, en las tripas de la casa, nos esperaban Solano y Gloria, en su nuevo e improvisado estudio. Una operación de estómago, utilizando puntales de ladrillo y algún que otro ingenio, había convertido aquel oscuro lugar doméstico en una fábrica de ideas por un extraño capricho del destino.

En aquella casa me quedé durante unos días. Me quedé lo suficiente como para descubrir que desde aquella cueva se está gestando el ADN de una nueva identidad nacional. Desde allí y, como es natural, desde el taller de Javier Corvalán, antiguo socio y amigo, o desde las casas de Joseto, inseparable compañero de Solano, o de Lucho, o de sus antiguos alumnos, Lukas o Miki. Una identidad cuyos matices se pueden intuir en el texto "Un fin del Mundo" que nos presenta Javier Corvalán dentro de este mismo número, o en las obras que se publican a continuación. 
Así fluyeron los días entre excursiones y asados. A veces con Solano y con Gloria, muchas veces con Joseto, a veces con Solanito, su hijo. Un arquitecto inteligente que me mostró su obra y el único lugar desde el que Asunción puede ver el río Paraguay, ItaPyta Punta, su válvula de escape, tal vez su futuro.

Rodeamos lagos y escalamos tapias, comimos, con las manos, sopa paraguaya y chipá bajo los techos de las reducciones jesuíticas. Me dijeron que un arquitecto de Barcelona se interesó especialmente, a su paso por el Chaco, en un cinturón de los indios Ayoreo. Lo usan como silla para descansar en cuclillas, rodeando con él sus riñones y sus rodillas. No lo compré, hubiera sido como engañar a un amigo con su propia mujer. Sin embargo, elegí el yacaré de madera más feo que encontré y dos o tres tortugas de palosanto. Para Abu una orquídea.

Siempre regresábamos al sótano, a la madriguera.

Tras muchas conversaciones, mientras sonaba Javier Calamaro, hermano de Andrés, en aquel rincón, a tumba abierta, sin máscaras, con tereré, con whisky, hablamos sobre sus ladrillos, sobre los reflejos del sepulcro de su padre, sobre los nuevos materiales, los enemigos, los amigos y, por supuesto, sobre Rafael Iglesia. Por segunda vez, no me pude contener: "iSolano! Eres más grande de lo que pensaba". Su risa se precipitó sin ningún complejo y nos abrazamos como si nos conociéramos desde el colegio.

Aquí, en este punto del viaje, comienza una nueva aventura editorial para amantes de la arquitectura de toda lberoamérica.

Tal vez estas palabras sean demasiado emocionales para representar el esfuerzo común de una publicación como rita_ y de una plataforma como redfundamentos que nos quiere hablar de Arquitectura desde el amparo de la Universidad. La universidad como lugar de reunión, como foro de experimentación e investigación de lo que ha sucedido, sucede y sucederá a nuestro alrededor.

Desde rita_ llegamos a las universidades, con una mochila de montaña, cargada a la espalda, llena de experiencias. A través de redfundamentos salimos de la universidad con la intención de ir llenándola poco a poco. Obras y arquitectos, textos y autores, instituciones y personas se dan cita en este primer número que parte desde Paraguay.

Y ahora sí, el consejo de redacción quiere agradecer su apoyo a todas las Escuelas y Facultades de Arquitectura que se han comprometido con este proyecto independiente y a quienes las representan.

Queremos compartir y ceder estas páginas a los autores que nos muestran un mundo más completo y preciso a través de sus mejores textos de investigación. Y por último, queremos dar las gracias a la Comisión Nacional Evaluadora de la Actividad Investigadora (Ministerio de Ciencia e Innovación, Resolución 18939 de 11 de noviembre de 2008 de la Presidencia de la CNEAl, Apéndice I, BOE $n^{\circ} 282$, de 22.11.08) porque nos ha brindado la coartada que nos permite existir. 